\title{
A comparison of complement fixation, indirect immunofluorescence for viral late antigens, and anti-complement immunofluorescence tests for the detection of cytomegalovirus specific serum antibodies
}

\author{
P. D. GRIFFITHS, K. J. BUIE, AND R. B. HEATH \\ From the Department of Virology, St. Bartholomew's Hospital, London EC1A 7BE, UK
}

SUMMARY It was shown that, on average, the titres of the sera obtained by both the anti-complement immunofluorescence (ACIF) and indirect immunofluorescence for viral late antigens (IFA-LA) procedures were approximately eight times higher than those obtained by complement fixation. There was no significant difference between the mean ACIF and IFA-LA titres, but the former method was preferred because it was not affected by non-specific staining.

When 406 sera were screened for the presence or absence of antibodies, only five sera (1.2\%) gave discordant results with the three tests. None of the tests could detect all of the sera that contained specific antibodies while each test detected over $98 \%$ of these sera. Thus, the increased sensitivity of the immunofluorescence procedures did not result in an appreciably increased rate of detection of cytomegalovirus seropositive sera.

Infection with cytomegalovirus (CMV) is usually asymptomatic, but several studies have shown that this virus is an important cause of intrauterine infection (Stern and Tucker, 1973; Reynolds et al., 1974; Hanshaw et al., 1976) and that it can also occasionally produce serious disease in immunocompromised patients (Abdallah et al., 1976).

The infection can be diagnosed serologically, and the complement fixation (CF) test is the method most widely used. It is simple to perform, gives reproducible results, and is suitable for testing large numbers of sera, but its main disadvantage is lack of sensitivity (Lang and Noren, 1968; Nagington, 1971).

An indirect immunofluorescence assay for viral late antigens (IFA-LA) has been shown to detect CMV specific antibodies in sera more frequently than the CF test (Stagno et al., 1975a and b). Unfortunately, use of the IFA-LA test is complicated by non-specific binding of IgG to the Fc receptors, which are produced when CMV infects fibroblast cell cultures (Keller et al., 1976). Some experience

Received for publication 6 February 1978 with this technique is required before it is possible to differentiate reliably between specific and nonspecific fluorescence.

An alternative staining procedure, the anticomplement immunofluorescence test (ACIF), has been described for CMV, and this method is not affected by binding of IgG to the Fc receptors (Keller et al., 1976).

The sensitivity of the CF test can be improved by using an alkaline glycine-extracted (GE) antigen first described by Krech et al. (1971). It has been shown that antibodies are detected by CF more frequently when a GE antigen is used, rather than when antigen is prepared by simply freezing and thawing CMV-infected cells (Cremer et al., 1975).

Betts et al. (1976) compared the IFA-LA and GE-CF methods for measuring CMV antibodies in sera from renal transplant recipients and donors. The IFA-LA method gave higher titres than the GE-CF test, but both tests detected a virtually identical number of seropositive sera.

In this study we have tested sera from pregnant women to compare the sensitivity of the CF, IFA-LA, and ACIF methods of detecting specific CMV anti827 
bodies and have assessed the efficiency with which the methods detected serum antibodies against this virus.

\section{Material and methods}

\section{STUDY POPULATION}

Serum specimens were obtained from $\mathbf{4 0 6}$ women who presented consecutively to this hospital for antenatal care.

\section{SEROLOGICAL METHODS}

The AD-169 strain of CMV was employed as antigen for all serological tests.

Complement fixation tests were performed in plastic microplates with a commercially available GE antigen (Hoechst Pharmaceuticals). Two units of antigen, complement (Tissue Culture Services Ltd), and haemolytic serum (Wellcome Reagents Ltd) were used. Sheep red cells were obtained from Tissue Culture Services Ltd. The reciprocal of the highest dilution of serum which showed no haemolysis was taken as the end-point.

The ACIF and IFA-LA tests were performed by a modification of the methods described by Stagno et al. (1975a and b). Briefly, a suspension of trypsinised human embryo lung fibroblasts was mixed with virus in the ratio of 0.1 TCD 50 per cell. Fifty microlitres of the cell-virus suspension was then placed onto each well of polytetrafluoro-ethylene (PTFE) coated microscope slides (C. A. Hendley and Co), and these slides were incubated at $37^{\circ} \mathrm{C}$ for four hours in a $\mathrm{CO}_{2}$-incubator to permit attachment of the cells to the glass. The slides were then flooded with growth medium and incubation was continued. After 72 hours these cell preparations were air dried, fixed in cold acetone $\left(4^{\circ} \mathrm{C}\right)$, and stored at $-20^{\circ} \mathrm{C}$ until required.

To perform the immunofluorescence tests, appropriate dilutions of each serum, as indicated in the test, were placed onto duplicate wells of the prepared slides and were incubated at $37^{\circ} \mathrm{C}$ for 60 minutes in a humid atmosphere. After thorough washing the preparations were stained by either the ACIF or IFA-LA method.

For the ACIF test, a 1:30 dilution of a human serum known not to contain CMV antibodies was added, and the slides were incubated at $37^{\circ} \mathrm{C}$ for 60 minutes. The slides were washed thoroughly and were then incubated at $37^{\circ} \mathrm{C}$ for a further 30 minutes with a 1:25 dilution of a commercially available fluorescein-conjugated rabbit anti-human C3 serum (Hoechst Pharmaceuticals). After washing, the slides were counterstained with $0.1 \%$ Evans blue and were examined with a Reichert Fluorpan immunofluorescence microscope.
For the IFA-LA test, a 1:80 dilution of a commercially available fluorescein-conjugated antihuman IgG serum (Wellcome Reagents Ltd) was added, and the slides were incubated at $37^{\circ} \mathrm{C}$ for 60 minutes. After thorough washing the preparations were counterstained with Evans blue and examined as described above.

For both immunofluorescence tests, the reciprocal of the highest dilution of serum which showed unequivocal fluorescence was taken as the endpoint.

STATISTICAL ANALYSIS

The relationships between the antibody titres obtained with the three serological methods were analysed by Spearman's rank correlation coefficient method.

\section{Results}

SCREENING SERA FOR PRESENCE OR ABSENCE OF ANTIBODIES TO CMV BY CF, ACIF, AND IFA-LA TESTS

A 1:8 dilution of serum from each of 406 consecutive patients attending the antenatal clinic of this hospital was tested by CF and both immunofluorescent procedures. The results of these screen tests are shown in Table 1.

Table 1 Results of screening 406 sera for presence or absence of antibodies against $C M V$ by $C F, A C I F$, and IFA-LA tests

\begin{tabular}{|c|c|c|c|}
\hline \multicolumn{3}{|c|}{ Serological test } & \multirow{2}{*}{$\begin{array}{l}\text { No. of } \\
\text { sera }\end{array}$} \\
\hline$C F$ & $A C I F$ & $I F A-L A$ & \\
\hline \multicolumn{4}{|c|}{ Concordant results } \\
\hline +ve & $+\mathbf{v e}$ & + ve & 248 \\
\hline- ve & - ve & - ve & 153 \\
\hline \multicolumn{4}{|c|}{ Discordant results } \\
\hline- ve & +ve & $+\mathbf{v e}$ & 3 \\
\hline- ve & $+\mathrm{ve}$ & - ve & 1 \\
\hline +ve & - ve & - ve & 1 \\
\hline
\end{tabular}

+ve, antibody detected; - ve, antibody not detected

It will be seen that 401 of the 406 sera $(\mathbf{9 8 . 8 \% )}$ were either seronegative or seropositive in all assays. Only five of the 406 sera $(1.2 \%)$ gave results which were consistently discordant.

Table 2 shows in more detail the results obtained with the five sera that gave these discordant results. For each serum the original screen result is shown along with the antibody titre subsequently found in each assay. Three of the sera were seropositive in both immunofluorescence assays but seronegative in the CF test; this is probably a reflection of the increased sensitivity of the immunofluorescence assays. The third serum sample, although negative 
Table 2 Serological results obtained with five sera which consistently gave discordant results in $C F, A C I F$, and IFA-LA tests

\begin{tabular}{|c|c|c|c|c|c|c|}
\hline \multirow{3}{*}{$\begin{array}{l}\text { Serum } \\
\text { no. }\end{array}$} & \multicolumn{6}{|l|}{ Serological test } \\
\hline & \multicolumn{2}{|l|}{$C F$} & \multicolumn{2}{|l|}{$A C I F$} & \multicolumn{2}{|l|}{$I F A-L A$} \\
\hline & Initial screen & Re-test titre & Initial screen & Re-test titre & Initial screen & Re-test titre \\
\hline $\begin{array}{l}1 \\
2 \\
3 \\
4 \\
5\end{array}$ & $\begin{array}{l}\text { - ve } \\
\text { - ve } \\
\text { - ve } \\
\text { - ve } \\
\text { +ve }\end{array}$ & $\begin{aligned}<2 \\
<8 * \\
\quad 4 \\
<8(\mathrm{AC} \dagger) \\
\quad 8\end{aligned}$ & $\begin{array}{l}\text { +ve } \\
\text { + ve } \\
\text { +ve } \\
\text { +ve } \\
\text { - ve }\end{array}$ & $\begin{array}{r}32 \\
16 \\
16 \\
16 \\
<2\end{array}$ & $\begin{array}{l}\text { +ve } \\
\text { +ve } \\
\text { +ve } \\
\text { - ve } \\
\text { - ve }\end{array}$ & $\begin{array}{r}64 \\
32 \\
32 \\
<2 \\
<2\end{array}$ \\
\hline
\end{tabular}

*Insufficient serum to begin dilution series at $1: 2$

+Anticomplementary activity to a titre of 4

when screened at a dilution of $1: 8$, was found to be positive at a dilution of $1: 4$.

The fourth serum sample was seropositive in the ACIF test but seronegative in the other two assays. This result may indicate a slight superiority of the ACIF test over the IFA-LA test for detecting low-titre antibodies, possibly because of the difficulty of distinguishing staining of the Fc receptor in the latter test. However, this same serum sample showed anticomplementary activity to a titre of 4 in the CF test, so it is possible that the ACIF test may also, in some way, have been affected by this activity.

The fifth serum sample had a CF titre of 8 but was seronegative in both of the immunofluorescence assays. This difference was consistently obtained and suggests the possibility that the CF test may occasionally detect specific antibodies of a different nature from those detected by the immunofluorescence assays.

A total of 253 sera were shown to be seropositive by at least one of the three methods. None of the three tests could individually detect all of these sera but the ACIF test detected 252 (99.6\%), the IFA-LA test $251(99.2 \%)$, and the CF test $249(98.4 \%)$. Thus, there was remarkably little difference in the efficiency with which each method detected specific antibody.

ASSAY OF SEROPOSITIVE SERA TO DETERMINE COMPARATIVE SENSITIVITY OF CF, ACIF,

AND IFA-LA PROCEDURES

One hundred sera, which on initial screening had been shown to be seropositive in the CF, ACIF, and IFA-LA tests, were subsequently titrated by the same three methods.

Figure 1 shows the distributions of the titres of antibody present in these 100 sera. It is evident that the titres obtained in the two immunofluorescence assays are virtually identical and that both of these tests are far more sensitive than the CF test. These differences are reflected in the geometric mean

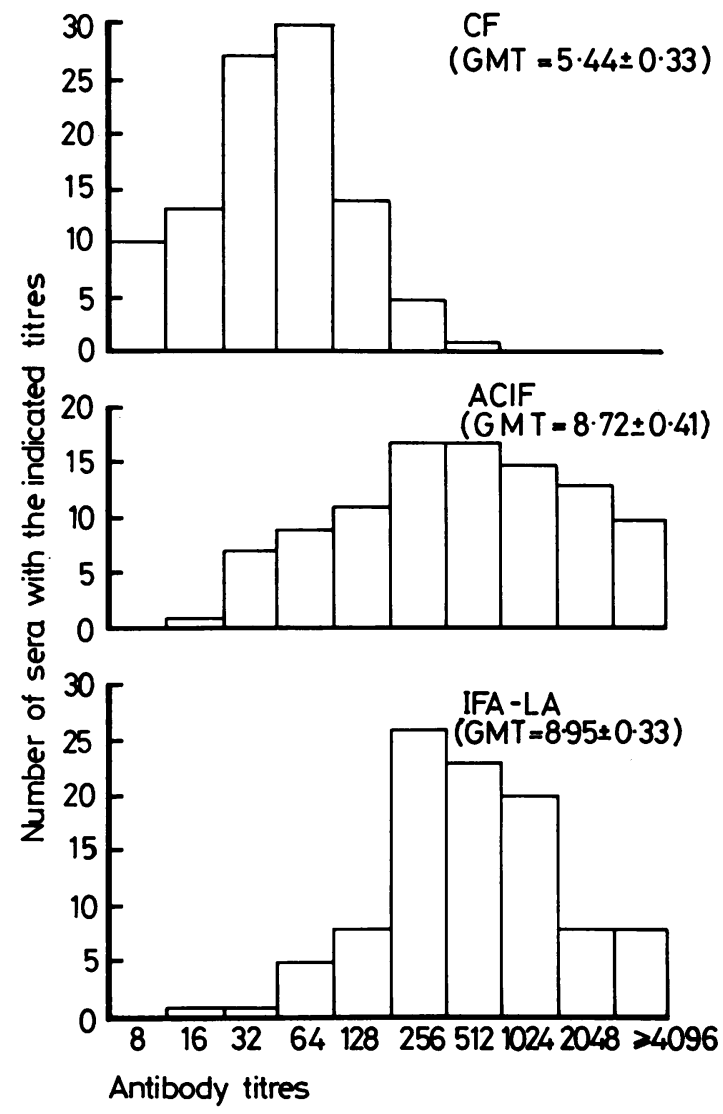

Fig. 1 Distributions of antibody titres of 100 known seropositive sera obtained by the CF, ACIF, and IFA-LA methods. GMTs (geometric mean titres) are expressed in $\log _{2}$ units \pm 2 standard errors of the mean.

titres (GMTs) calculated for each test. The GMTs for the two immunofluorescence assays do not differ significantly from each other, yet each is approximately eight-fold greater than the GMT calculated for the CF test. 


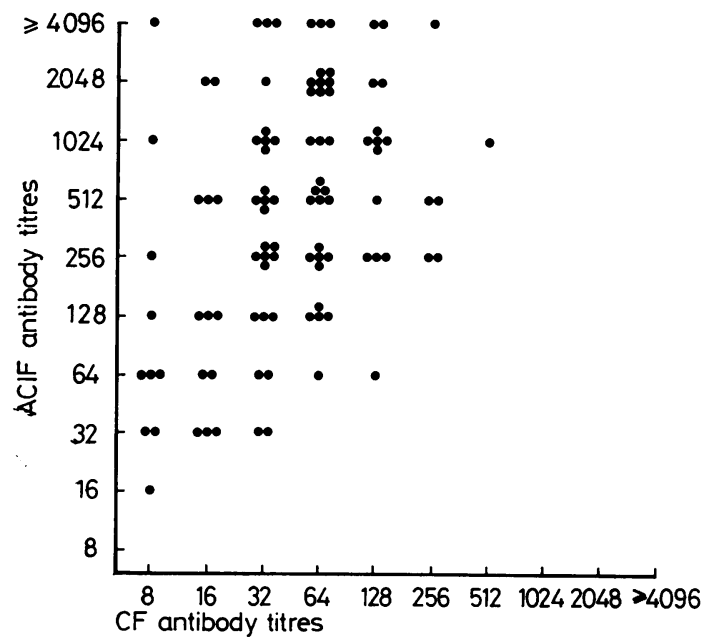

Fig. 2 Correlation between CF and ACIF titres of 100 sera known to contain antibodies against $C M V$.

Figure 2 shows the comparative distribution of the antibody titres obtained by complement fixation and anti-complement immunofluorescence. It will be seen that, while the ACIF titres are generally higher than the CF titres, there was obvious correlation between the results of the two tests. This correlation was analysed statistically using Spearman's rank correlation method, and the results are shown in Table 3, which also shows the correlation co-

Table 3 Correlation between specific antibody titres detected in 100 sera by CF, IFA-LA, and ACIF methods

\begin{tabular}{lll}
\hline Comparative assays by: & $r^{*}$ & Significance \\
\hline CF and ACIF & 0.39 & $P<0.001$ \\
CF and IFA-LA & 0.37 & $P<0.001$ \\
ACIF and IFA-LA & 0.55 & $P<0.001$ \\
\hline
\end{tabular}

* Correlation coefficient calculated by Spearman's rank correlation method

efficients for the other two combinations of pairs of tests (CF with IFA-LA, and ACIF with IFA-LA.) All three correlations are highly significant $(P<0.001)$, which suggests that, in general, the three assays are detecting similar degrees of immune responsiveness to CMV. The best correlation observed was between the two immunofluorescence assays, despite the error inherent in the method used to estimate their end-points. In contrast, the correlation coefficients obtained with either immunofluorescence assay and the CF test were low. This suggests that the CF test may be measuring different antibodies from those measured by the immunofluorescence methods.

\section{Discussion}

Our studies have shown that $\mathrm{CF}$ with a glycineextracted antigen and the ACIF and IFA-LA immunofluorescence procedures can satisfactorily detect specific CMV antibodies. Both the ACIF and IFA-LA procedures were found to be appreciably more sensitive than GE-CF, but there was no significant difference between the sensitivities of the two immunofluorescence assays. We consider ACIF to be the immunofluorescence method of choice because, unlike IFA-LA, it is not affected by non-specific staining produced by binding of IgG to Fc receptors on CMV-infected cells. The ACIF test was therefore very much easier to read, and this more than compensated for the extra step required in the staining procedure.

In practice, however, the more sensitive immunofluorescence procedures did not detect an appreciably greater number of sera with specific CMV antibodies than did the GE-CF test. Essentially similar results with sera from renal transplant patients have been obtained by Betts et al. (1976), who compared IFALA with GE-CF. Provided that a good antigen is used, it appears that the simpler CF test is a satisfactory method for detecting antibodies against CMV and is, of course, perfectly adequate when acute and convalescent sera are available from patients. The type of CF antigen used appears to be important for, in earlier studies, it was shown that a nonglycine-extracted CF antigen failed to detect an appreciable number of sera with antibodies detect. able by IFA-LA (Stagno et al., 1975a and b).

The extra sensitivity of the immunofluorescence procedures could be of value on occasions when it is critically important to know the CMV immune status of an individual. For example, it may be important to have sensitive tests if it is subsequently shown to be necessary to match potential renal transplant donors and recipients for evidence of infection with this virus.

It was of interest that, although there was unequivocal correlation between both the CF:ACIF and CF:IFA-LA titres, the correlation coefficients were of low order. Furthermore, one serum contained specific CF antibodies but was seronegative in both the ACIF and IFA-LA tests. Betts et al. (1976) identified a similar serum sample, which possessed GE-CF antibodies but lacked IFA-LA antibodies. This suggests that the antibodies detected by the CF and immunofluorescence tests may not be the same, but, clearly, more evidence is required on this point.

We thank C. Ronalds, FIMLS, for technical assis- 
tance, Jane Wadsworth for statistical advice, and the Wellcome Foundation for financial support.

\section{References}

Abdallah, P. S., Mark, J. B. D., and Merigan, T. C. (1976). Diagnosis of cytomegalovirus pneumonia in compromised hosts. American Journal of Medicine, 61, 326-332.

Betts, R. F., George, S. D., Rundell, B. B., Freeman, R. B., and Douglas, R. G. Jr. (1976). Comparative activity of immunofluorescent antibody and complementfixing antibody in cytomegalovirus infection. Journal of Clinical Microbiology, 4, 151-156.

Cremer, N. E., Schmidt, N. J., Jensen, F., Hoffman, M., Oshiro, L. S., and Lennette, E. H. (1975). Complementfixing antibody in human sera reactive with viral and soluble antigens of cytomegalovirus. Journal of Clinical Microbiology, 1, 262-267.

Hanshaw, J. B., Scheiner, A. P., Moxley, A. W., Caev, L., Abel, V., and Scheiner, B. A. (1976). School failure and deafness after "silent" congenital cytomegalovirus infection. New England Journal of Medicine, 295, 468-470.

Keller, R., Peitchel, R., Goldman, J. N., and Goldman, M. (1976). An IgG-Fc receptor induced in cytomegalovirus- infected human fibroblasts. Journal of Immunology, 116, 772-777.

Krech, U., Jung, M., and Sonnabend, W. (1971). A study of complement-fixing, immunofluorescent, and neutralising antibodies in human cytomegalovirus infections.
Zeitschrift für Immunitätsforschung, experimentelle und klinische Immunologie, 141, 411-429.

Lang, D. J., and Noren, B. (1968). Cytomegaloviremia following congenital infection. Journal of Pediatrics, 73, 812-819.

Nagington, J. (1971). Cytomegalovirus antibody production in renal transplant patients. Journal of Hygiene, 69, 645-660.

Reynolds, D. W., Stagno, S., Stubbs, K. G., Dahle, A. J., Livingston, M. M., Saxon, S. S., and Alford, C. A. (1974). Inapparent congenital cytomegalovirus infection with elevated cord IgM levels: causal relation with auditory and mental deficiency. New England Journal of Medicine, 290, 291-296.

Stagno, S., Reynolds, D. W., Tsiantos, A., Fucillo, D. A., Long, W., and Alford, C. A. (1975b). Comparative serial virologic and serologic studies of symptomatic and subclinical congenitally and natally acquired cytomegalovirus infections. Journal of Infectious Diseases, 132, 568-577.

Stagno, S., Reynolds, D., Tsiantos, A., Fuccillo, D. A., Smith, R., Tiller, M., and Alford, C. A., Jr. (1975a). Cervical cytomegalovirus excretion in pregnant and non-pregnant women: suppression in early gestation. Journal of Infectious Diseases, 131, 522-527.

Stern, H., and Tucker, S. M. (1973). Prospective study of cytomegalovirus infection in pregnancy. British Medical Journal, 2, 268-270.

Requests for reprints to: Dr P. D. Griffiths, Virology Department, St. Bartholomew's Hospital, West Smithfield, London EC1A 7BE. 